\title{
Improvement of pharmacokinetic and antitumor activity of layered double hydroxide nanoparticles by coating with PEGylated phospholipid membrane
}

\author{
This article was published in the following Dove Press journal: \\ International Journal of Nanomedicine \\ 21 October 2014 \\ Number of times this article has been viewed
}

Mina Yan ${ }^{1,2}$

Zhaoguo Zhang ${ }^{2}$

Shengmiao $\mathrm{Cui}^{3}$

Ming Lei ${ }^{2}$

Ke Zeng ${ }^{2}$

Yunhui Liao ${ }^{2}$

Weijing $\mathrm{Chu}^{2}$

Yihui Deng'

Chunshun Zhao ${ }^{2}$

'School of Pharmacy, Shenyang Pharmaceutical University, Shenyang, People's Republic of China;

${ }^{2} S c h o o l$ of Pharmaceutical Sciences,

Sun Yat-sen University, ${ }^{3}$ Guangdong

Pharmaceutical University, Guangzhou,

People's Republic of China
Correspondence: Chunshun Zhao School of Pharmaceutical Sciences, Sun Yat-Sen University, 132 Waihuan East Road, Guangzhou 510006,

People's Republic of China

Tel +86 2039943 II 8

Fax +86 2039943118

Email zhaocs@mail.sysu.edu.cn

Yihui Deng

School of Pharmacy, Shenyang

Pharmaceutical University, 103 Wenhua Road, Shenyang 110016 , People's Republic of China

Tel +86242398 6316

Fax +862423986316

Email pharmdeng@gmail.com
Abstract: Layered double hydroxide (LDH) has attracted considerable attention as a drug carrier. However, because of its poor in vivo behavior, polyethylene glycolylated (PEGylated) phospholipid must be used as a coformer to produce self-assembled core-shell nanoparticles. In the present study, we prepared a PEGylated phospholipid-coated LDH (PLDH) (PEG-PLDH) delivery system. The PEG-PLDH nanoparticles had an average size of $133.2 \mathrm{~nm}$. Their coreshell structure was confirmed by transmission electron microscopy and X-ray photoelectron spectroscopy. In vitro liposome-cell-association and cytotoxicity experiments demonstrated its ability to be internalized by cells. In vivo studies showed that PEGylated phospholipid membranes greatly reduced the blood clearance rate of LDH nanoparticles. PEG-PLDH nanoparticles demonstrated a good control of tumor growth and increased the survival rate of mice. These results suggest that PEG-PLDH nanoparticles can be a useful drug delivery system for cancer therapy.

Keywords: lipid membrane, positive charge, delivery system, cancer therapy

\section{Introduction}

Layered double hydroxides (LDHs) have been known for many decades as catalysts, ${ }^{1,2}$ traps for anionic pollutants, ${ }^{3,4}$ and flame retardants, ${ }^{5,6}$ but they were only successfully synthesized on the nanometer scale a few years ago, opening up a whole new field for their use in nanomedicine., ${ }^{7,8}$

LDHs, also known as hydrotalcite-like materials and as anionic (specifically, anionexchanging) clays, are a large group of natural and synthetic materials that are readily produced when suitable mixtures of metal salts are exposed to bases. ${ }^{9}$ LDHs consist of layers and contain the hydroxides of two or more different metal cations. They are positive charged which is neutralized by the incorporation of exchangeable anions. In general, the materials also contain various amounts of water hydrogen-bonded to the hydroxide layers and interlayer anions. In the cases considered here, the metal cations of LDHs are octahedrally coordinated by hydroxide groups. ${ }^{10,11}$ The LDH composition can be expressed in a general formula:

$$
\left[\mathrm{M}^{2+}{ }_{1-\mathrm{x}} \mathrm{M}_{\mathrm{x}}^{3+}(\mathrm{OH})_{2}\right]\left(\mathrm{A}_{\mathrm{x}}^{-} \cdot \mathrm{nH}_{2} \mathrm{O}\right)
$$

where $\mathrm{M}^{2+}$ and $\mathrm{M}^{3+}$ are the divalent and trivalent metal ions and $\mathrm{A}^{-}$is any type of anion. ${ }^{12}$ Many studies have demonstrated that anticancer drugs ${ }^{13-16}$ and genes ${ }^{7,17-20}$ could be successfully intercalated into the LDH layers. 
LDH nanoparticles exhibit low cytotoxicity and are highly biocompatible, as demonstrated by recent in vitro studies using a range of transformed and tumor-derived cell lines. ${ }^{17,18}$ They can efficiently enter cells via the clathrin-mediated endocytosis pathway, which is the most common energydependent endocytosis. ${ }^{14,21,22}$ One of the most fascinating features of LDH nanoparticle-based delivery systems is that they can escape from the endolysosome. The intracellular pathway of LDH nanoparticles in human cells was investigated, and most particles were found to escape typical endolysosomal degradation when their size was around $100 \mathrm{~nm} .^{23}$

However, few reports have described the in vivo behavior of LDH nanoparticles. A pharmacokinetic study of LDH nanoparticles administered intraperitonealy was investigated earlier. ${ }^{15}$ However, intravenously administered LDH nanoparticles have not been studied. The positive surface charge of these nanoparticles, which allows avid association with negatively charged plasma proteins, adversely influences their pharmacokinetic behavior and reduces their blood residence time. ${ }^{24}$ Tolerability to the serum is crucial when considering the in vivo application of this carrier system. ${ }^{25,26}$ For this reason, there is certainly a need to cover LDH nanoparticles with a shell that can make them "invisible" in the blood and easy to modify.

In the present study, a novel delivery system was developed: polyethylene glycolylated (PEGylated) phospholipidcoated LDH (PLDH) (PEG-PLDH) nanoparticles (Figure 1). An anionic phospholipid, dioleoylphosphaidic acid (DOPA), served as a coating reagent after the formation of the nanosized LDH core loaded with methotrexate (MTX). DOPA

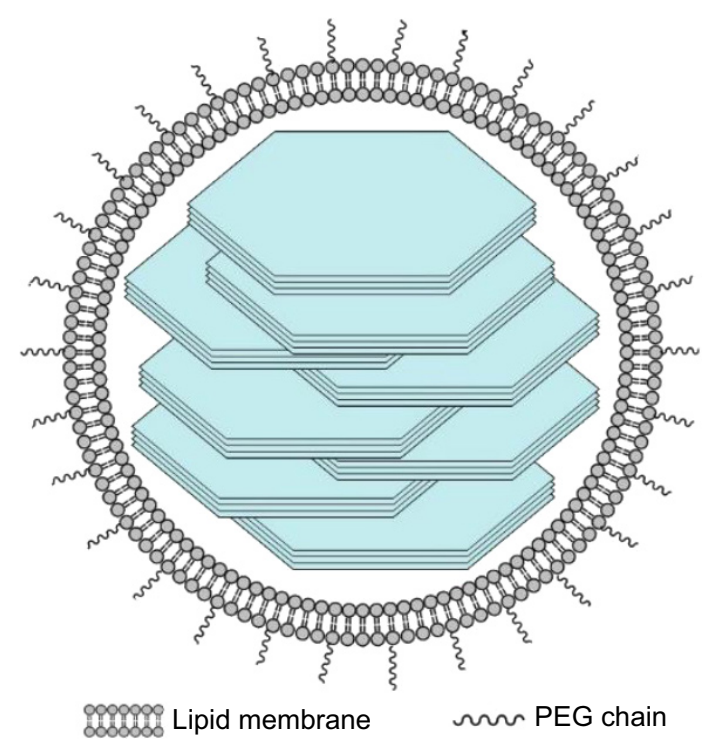

Figure I Proposed structure of PEGylated phospholipid coated layered double hydroxide nanoparticles.

Abbreviation: PEG, polyethylene glycol. was chosen as a lipid because it forms liposomes readily ${ }^{27}$ and has a negatively charged phosphatidic acid head group, which aids in the shielding of positive charged LDH. A PEG-lipid conjugate was also included in the leaflet lipids, to prolong circulation time. ${ }^{28} \mathrm{We}$ report here the preparation, properties, and in vitro and in vivo activity of this novel drug carrier.

\section{Materials and methods Materials}

Dioleoylphosphatidic acid (sodium salt) (DOPA) and cholesterol were purchased from Avanti Polar Lipids, Inc., (Alabaster, AL, USA). Distearoylphosphatidylethanolamine (DSPE) and distearoylphosphocholine (DSPC) were purchased from Genzyme Corp., (Cambridge, MA, USA). Methotrexate (MTX) was provided by Amresco LLC (Solon, OH, USA). The fluorescent dye, fluorescein isothiocyanate (FITC), was obtained from Sigma-Aldrich Corp (St Louis, MO, USA). Acetonitrile of high performance liquid chromatography (HPLC) analytical grade were provided by Dikma Technologies (Beijing, People's Republic of China). HeLa cells and 3T3 cells purchased from the Laboratory Animal Center of Sun Yat-sen University (Guangzhou, People's Republic of China) and were cultured with Dulbecco's modified Eagle's medium (DMEM) (SigmaAldrich Corp) supplemented with 10\% newborn calf serum (Life Technologies Corp., Carlsbad, CA, USA).

Sprague-Dawley rats $(220 \pm 20 \mathrm{~g})$ and Kunming mice $(20 \pm 2 \mathrm{~g}$ ) were supplied by the Laboratory Animal Center of Sun Yat-sen University. All experimental procedures were approved and supervised by the Institutional Animal Care and Use Committee of Sun Yat-sen University.

\section{Preparation of LDH-MTX and LDH-FITC nanoparticles}

Both the LDH-MTX and LDH-FITC nanoparticle suspensions were prepared with a quick precipitation and subsequent hydrothermal treatment. ${ }^{12,29}$ In brief, $3.0 \mathrm{mmol}$ of $\mathrm{MgCl}_{2}$ and $1.0 \mathrm{mmol}$ of $\mathrm{AlCl}_{3}$ were dissolved in $10 \mathrm{~mL}$ deionized water. This salt solution was then rapidly (within 5 seconds) added to a basic solution $(40 \mathrm{~mL})$ containing $6.0 \mathrm{mmol}$ of $\mathrm{NaOH}$ and $0.1 \mathrm{mmol}$ of MTX (or $0.025 \mathrm{mmol}$ of FITC) to generate the precipitate of LDH-MTX (or LDH-FITC). After 10 minutes of stirring in a $\mathrm{N}_{2}$ stream at room temperature, the precipitate was collected via centrifugation and washed twice. Then the washed precipitate was manually dispersed in $20 \mathrm{~mL}$ of deionized water and placed in a $25 \mathrm{~mL}$ autoclave with Teflon linen, followed by hydrothermal treatment at $100^{\circ} \mathrm{C}$ (or $80^{\circ} \mathrm{C}$ ) in an oven for 6 hours (or 2 hours) to produce a suspension of LDH-MTX (or LDH-FITC) nanoparticles. 


\section{Preparation of PEG-PLDH-MTX and PEG-PLDH-FITC nanoparticles}

Both the PEG-PLDH-MTX and PEG-PLDH-FITC nanoparticle suspensions were prepared by self-assembly. Then $3.0 \mathrm{mmol}$ of DOPA, $2.4 \mathrm{mmol}$ of DSPC, $2.0 \mathrm{mmol}$ of cholesterol, and 0.6 mmol of DSPE-PEG(2000) were dissolved in $\mathrm{CHCl}_{3}$ and dried under a $\mathrm{N}_{2}$ stream. A trace amount of chloroform was removed by keeping the lipid film under a vacuum. The lipid film was hydrated with $200 \mu \mathrm{L}$ phosphate-buffered saline (PBS) $(\mathrm{pH}$ 7.4) to produce an empty liposome suspension. Then $200 \mu \mathrm{L}$ LDH-MTX (or LDH-FITC) nanoparticle suspension was added to the liposomes. The mixture was sonicated (in a water bath) using a laboratory ultrasonic cleaning machine (SB-5200DTN; Ningbo Scientz Biotechnology Co., Ltd., Zhejiang, People's Republic of China) at $250 \mathrm{~W}$ for 10 minutes.

\section{Size and zeta potential}

The average hydrodynamic diameter, polydispersity index (PDI), and zeta potential of the nanoparticles were determined by dynamic light scattering (DLS), using a Malvern Zetasizer Nano ZS90 (Malvern Instruments, Malvern, UK). The temperature of the cell was kept constant at $25^{\circ} \mathrm{C}$. The zeta potential was calculated from the electrophoretic mobility using the Smoluchowski equation. ${ }^{30}$ Samples of the prepared complexes were diluted in distilled water and measured at least three times. Size results were given as intensity distribution by the mean diameter with its standard deviation.

\section{Transmission electron microscopy (TEM)}

Size distribution was confirmed by using TEM. The samples were put on carbon Formvar-coated grids, negatively stained with uranyl acetate $1.5 \%$, and observed using a JEOL JEM1400 instrument (JEOL, Tokyo, Japan) $(120 \mathrm{kV})$.

\section{X-ray photoelectron spectroscopy (XPS)}

LDH and PEG-PLDH nanoparticles and empty liposome suspension were lyophilized (ALPHA1-4/LSC Freeze-drier; SciQuip Ltd, Shrewsbury, UK) before being transferred into the XPS instrument (ESCALab 250; Thermo Fisher Scientific, Inc., Waltham, MA, USA), where the analysis was performed. The sample of PEG-PLDH nanoparticles was finely ground with a mortar for the second round of testing.

\section{Cell culture}

HeLa cells and 3T3 cells were cultured in DMEM supplemented with $10 \%$ newborn calf serum and antibiotics (streptomycin $100 \mathrm{U} / \mathrm{mL}$ and penicillin $100 \mathrm{U} / \mathrm{mL}$ ) at $37^{\circ} \mathrm{C}$, in humidified air with $5 \% \mathrm{CO}_{2}$.

\section{Cellular internalization}

Cellular uptake of nanoparticles was visualized with confocal microscopy. HeLa cells $\left(1 \times 10^{5}\right.$ cells per well $)$ were grown on circular glass cover slips placed in 24-well plates. The following day, cells were exposed to LDH or PEG-PLDH nanoparticles for 1 hour, 4 hours, 24 hours, or 48 hours. After the incubation period, the cells on the cover slips were washed with PBS (three times). The cover slips were mounted on microscope slides, with mounting medium containing 4',6-diamidino-2-phenylindole (DAPI) (Vectashield ${ }^{\circledR}$ H-1200; Vector Laboratories, Inc., Burlingame, CA, USA) and viewed with a Zeiss confocal laser scanning microscope (Zeiss LSM 710; Carl Zeiss Meditec, Jena, Germany).

\section{Cell cytotoxicity assay}

The cytotoxicity of free-MTX, LDH-MTX, and PEGPLDH-MTX nanoparticles on HeLa cells and 3T3 cells was examined via 3-(4,5-dimethyl-2-thiazolyl)-2,5-diphenyl-2-H-tetrazolium bromide (MTT) assay. Briefly, cells were seeded in $96-$ well plates at a density of $1 \times 10^{4}$ cells per well and incubated for 24 hours. Then, the cells were treated with serial concentrations of free-MTX, LDHMTX, or PEG-PLDH-MTX nanoparticles. After 48 hours of incubation, $10 \mu \mathrm{L}$ of MTT solution $(5 \mathrm{mg} / \mathrm{mL})$ was added to each well and incubated for another 4 hours. Finally, the medium was replaced with $150 \mu \mathrm{L}$ of dimethylsulfoxide (DMSO), and the optical density was determined with a microplate reader at a wavelength of $570 \mathrm{~nm}$, in triplicate.

\section{Interaction of nanoparticles with plasma proteins}

Serum obtained from the periorbital vein of Sprague-Dawley rats was used to assess the interaction with PEG-PLDH nanoparticles. LDH or PEG-PLDH nanoparticle suspension was added to serum, with a ratio of 1:100.

\section{Pharmacokinetic study}

Eighteen Sprague-Dawley rats $(230 \pm 20 \mathrm{~g})$ were randomly assigned to three groups for pharmacokinetic investigation. Tail veins of rats in each of the three groups were injected with free-MTX, LDH-MTX, or PEG-PLDH-MTX nanoparticles at an equivalent dose of $2.5 \mathrm{mg} / \mathrm{kg}$ MTX. At scheduled points in time $(0.083,0.25,0.5,1,2,4$, and 8 hours after injection), $0.4 \mathrm{~mL}$ of blood was collected from the periorbital vein. Protein precipitation was performed prior to HPLC analysis. Briefly, $100 \mu \mathrm{L}$ blood samples were mixed with 
$50 \mu \mathrm{L}$ perchloric acid (17.5\%) and $50 \mu \mathrm{L}$ of $20 \mu \mathrm{g} / \mathrm{mL}$ salicylic acid solution as an internal standard. The samples were extracted on a vortex mixer for 1 minute and then centrifuged at $10,000 \mathrm{rpm}$ for 10 minutes with $20 \mu \mathrm{L}$ of supernatant, then collected for HPLC analysis.

\section{Chemotherapy study}

The antitumor efficacy of free-MTX, LDH-MTX, and PEG-PLDH nanoparticles was evaluated in Kunming mice inoculated subcutaneously in the right flank with $0.2 \mathrm{~mL}$ PBS containing $1 \times 10^{7} \mathrm{~S}-180$ cells. The MTX dose schedule started 3 days after tumor cell transplantation, to mimic early stage tumor growth. Then 24 mice bearing S-180 subcutaneous tumors were randomly assigned to four groups: (1) dextrose 5\% group (control); (2) free-MTX group; (3) LDH-MTX group; and (4) PEG-PLDH-MTX group. Mice were treated with drug or $5 \%$ glucose (control) every other day until five administrations were completed. Tumor volume was calculated by using mean diameter, measured with vernier calipers and using the formula

$$
\mathrm{v}=0.5 \times \mathrm{a} \times \mathrm{b}^{2}
$$

where $\mathrm{a}$ and $\mathrm{b}$ are the largest and the smallest diameter, respectively (short axis squared). Body weight was measured every other day.

\section{Statistical analysis}

Statistical analyses were performed using SPSS Statistics for Windows, Version 13.0 software (SPSS Inc., Chicago, IL, USA). One-way analysis of variance (ANOVA) and the least significant difference test were employed to analyze the in vivo data.

\section{Results and discussion Characterization}

Average particle sizes of the LDH and PEG-PLDH were $104.4 \pm 18.2 \mathrm{~nm}$ and $133.2 \pm 20.7 \mathrm{~nm}$, respectively; PDIs were 0.121 and 0.173 , respectively (Figure 2A). The result was confirmed using TEM for LDH and PEG-PLDH (Figure 2B). The average zeta potential values of LDH and PEG-PLDH were $39.2 \pm 1.2 \mathrm{mV}$ and $-31.4 \pm 4.7 \mathrm{mV}$, respectively.

The formation ofPEG-PLDHnanoparticles is a self-assembly process. Empty liposome suspension was achieved by sonication because amphiphilic phospholipids spontaneously formed micelles and self-aggregates. ${ }^{31}$ Particle size and PDIs increased considerably after the LDH nanoparticles were added to the liposome suspension (Table 1), indicating that the formation of PEG-PLDH nanoparticles had been initiated by the electrostatic interaction between negatively charged liposomes and positively charged LDH nanoparticles. It was hypothesized that the liposomes cracked to form a lipid membrane coating on the surface of LDH nanoparticles during

A
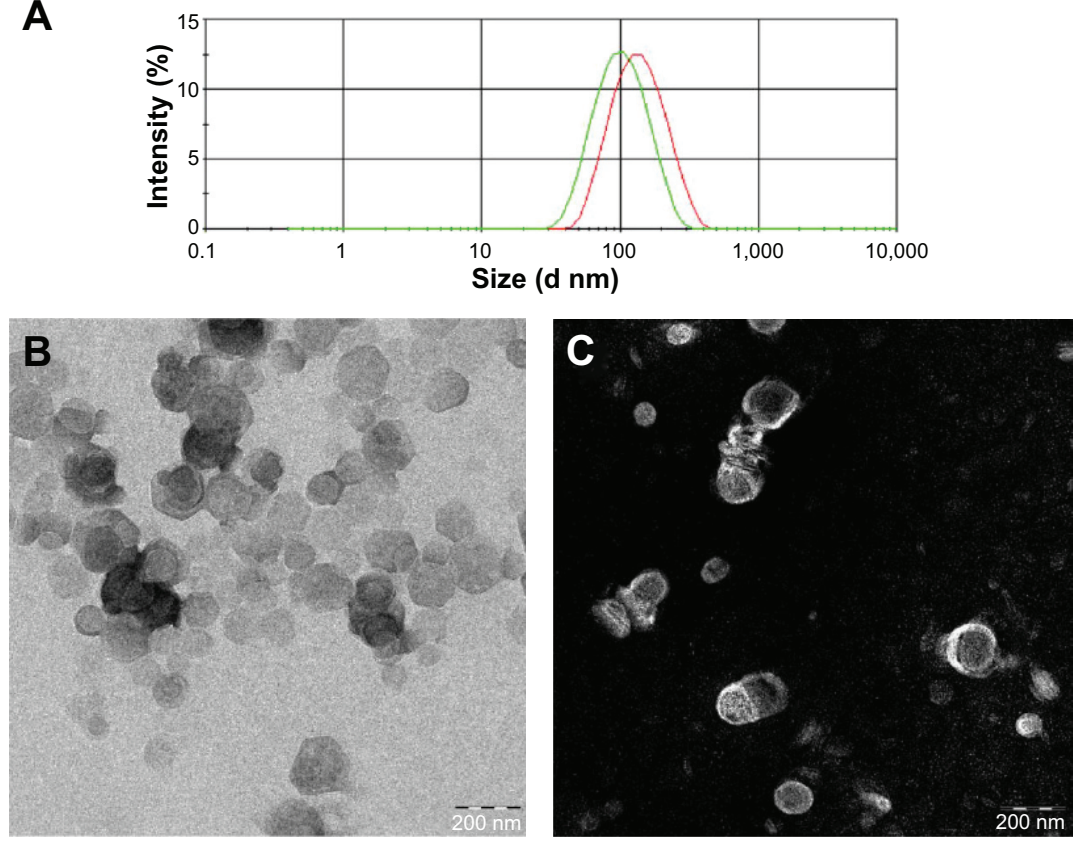

Figure 2 In vitro characteristics of LDH and PEG-PLDH nanoparticles.

Notes: (A) Particle size of LDH (green) and PEG-PLDH (red) nanoparticles. TEM photographs of LDH (B) and PEG-PLDH (C) nanoparticles.

Abbreviations: LDH, layered double hydroxide; PEG, polyethylene glycol; PEG-PLDH, PEGylated phospholipid-coated layered double hydroxide; TEM, transmission electron microscopy. 
Table I Influence of the sonication on the particle size of the mixture of empty liposomes and LDH nanoparticles

\begin{tabular}{lll}
\hline Samples & Size (nm) & $\begin{array}{l}\text { Polydispersity } \\
\text { index }\end{array}$ \\
\hline LDH & $104.4 \pm 18.2$ & 0.121 \\
Empty liposomes & $260.8 \pm 67.3$ & 0.397 \\
Mixture of empty liposomes & $3,067 \pm 1,628$ & 1.000 \\
$\begin{array}{l}\text { and LDH } \\
\text { Sonicated mixture of empty }\end{array}$ & $133.2 \pm 20.7$ & 0.173 \\
liposome and LDH & & \\
\hline
\end{tabular}

Note: Each value represents mean $\pm S D(n=3)$.

Abbreviations: LDH, layered double hydroxide; SD, standard deviation.

sonication since particle size and PDI decreased considerably after sonication (Table 1).

XPS is a surface chemical analysis technique usually used to analyze the surface chemistry of a material, but it is not well known in the determination of the composition of colloidal aggregates. For example, it has been used to investigate core-shell structure nanoparticles, such as poly(acryl acid)-modified $\mathrm{ZnO}$ nanoparticles ${ }^{32}$ and poly( $\varepsilon$-caprolactone)poly(ethylene glycol)-coated poly(isobutylcyanoacrylate) nanoparticles. ${ }^{33}$ Herein, XPS was used to confirm the coreshell composition of PEG-PLDH nanoparticles (Figure 3). As shown in Figure 3B, the ratio of Mg:Al:P was 1.3:1.9:6.8 for PEG-PLDH nanoparticles, but it became 3.4:3.4:3.2 after the sample was finely ground, which indicated that the lipid membrane was located on the surface of LDH nanoparticles.

\section{Cellular uptake in HeLa cells}

Confocal microscopy was used to investigate the cellular internalization of LDH and PEG-PLDH nanoparticles, which were labeled by FITC. To exert their therapeutic effects, nanoparticles must be taken up by the target cells.

The degree of internalization is greatly dependent on the physical characteristics of the nanoparticles. Charge, in particular, can alter nanoparticle-cell interactions and adhesion properties. ${ }^{34,35}$ Green fluorescence from the internalized PEG-PLDH nanoparticles was observed after 4 hours of incubation (Figure 4B) and was predominantly distributed in the cytoplasm after 24 hours of incubation (Figure 4C). In contrast, no fluorescence was observed in the group of LDH nanoparticles. However, the internalization of positively charged LDH nanoparticles was found to be significantly promoted by removal of newborn calf serum from the DMEM, suggesting that internalization of the LDH nanoparticles by cancer cells could be hampered by plasma proteins from serum in the DMEM. The weak fluorescence from internalized LDH in the absence of serum at 1 hour
(Figure 4A) could be ascribed to the electrostatic interaction between positively charged nanoparticles and the negatively charged cell membrane.

The mechanisms by which nanoparticles enter cells involve both the physical and interfacial characteristics of those nanoparticles, their interactions with the biological environment, and cell membrane properties. Nanoparticle size, shape, and surface characteristics (particularly charge and hydrophobicity) can influence the cellular uptake pathways. ${ }^{36} \mathrm{LDH}$ nanoparticles, which are positively charged, can enter cells through the clathrin-mediated endocytotic pathway. ${ }^{14,21,22}$ Negatively charged PEG-PLDH nanoparticles, however, may interact with cationic lipids (like sphingomyelin whose polar domain contains an amine group) on the cell membrane and then become internalized via caveolae-dependent endocytosis.

\section{Cell viability}

The MTX-free nanoparticles showed good cell viability over the concentration range used in this study - over $90 \%$ in all wells (Figure 5A). In vitro cytotoxicity of MTX, LDHMTX, and PEG-PLDH-MTX nanoparticles were evaluated on both HeLa (Figure 5B) and 3T3 (Figure 5C) cells. No significant difference in cellular viability was observed between MTX and PEG-PLDH-MTX. This could be attributed to the overexpression of folate receptors on the cell membrane. ${ }^{37}$ Free-MTX could be internalized into cancer cells via folate receptors ${ }^{38}$ while PEG-PLDH-MTX nanoparticles could be limited by PEGylation. ${ }^{39}$ LDH-MTX also showed similar cytotoxicity with PEG-PLDH-MTX (Figure 5B and C), which was unexpected since LDH nanoparticles could hardly be internalized into cells in the presence of serum (Figure 4). However, the interlayer anions in LDH were exchangeable, ${ }^{10}$ MTX intercalated into LDH may leak out and become internalized by the cells via folate receptor. This assumption was supported by the MTX release data (Figure S1).

\section{Interaction of nanoparticles with plasma proteins}

In order to assess the potential of the PEG-PLDH delivery system for intravenous administration, in vitro interaction of nanoparticles with plasma proteins was evaluated. Serum was obtained from Sprague-Dawley rats. As expected, precipitation was observed after LDH nanoparticle suspension was added to the serum (Figure 6), demonstrating that positively charged LDH nanoparticles could easily combine with negatively charged plasma proteins in serum, which 
A

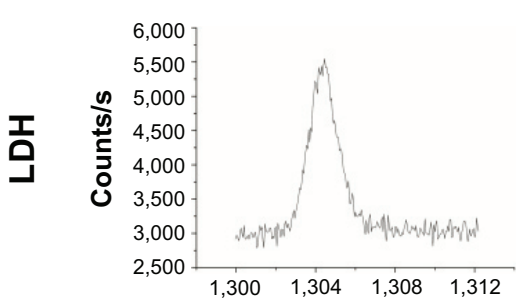

Binding energy (eV)
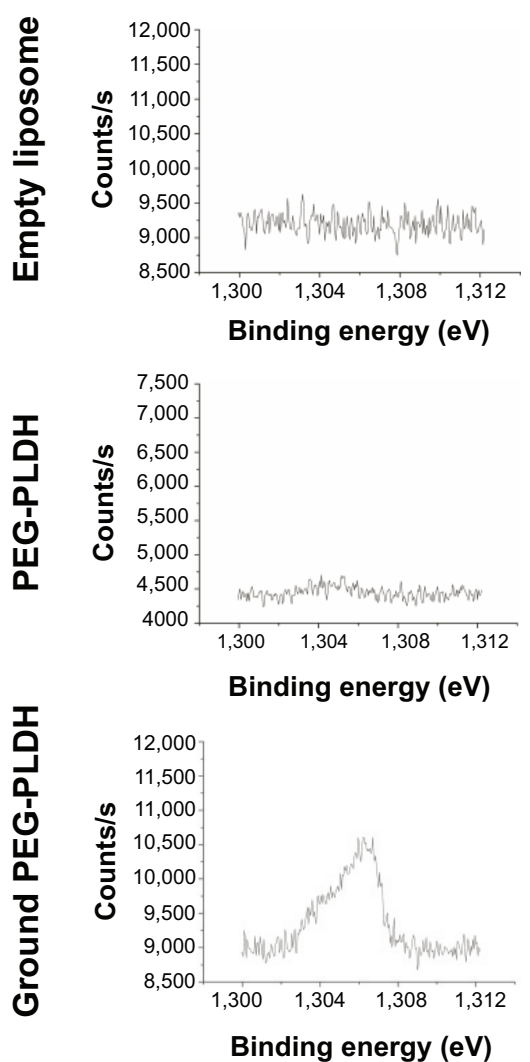

B

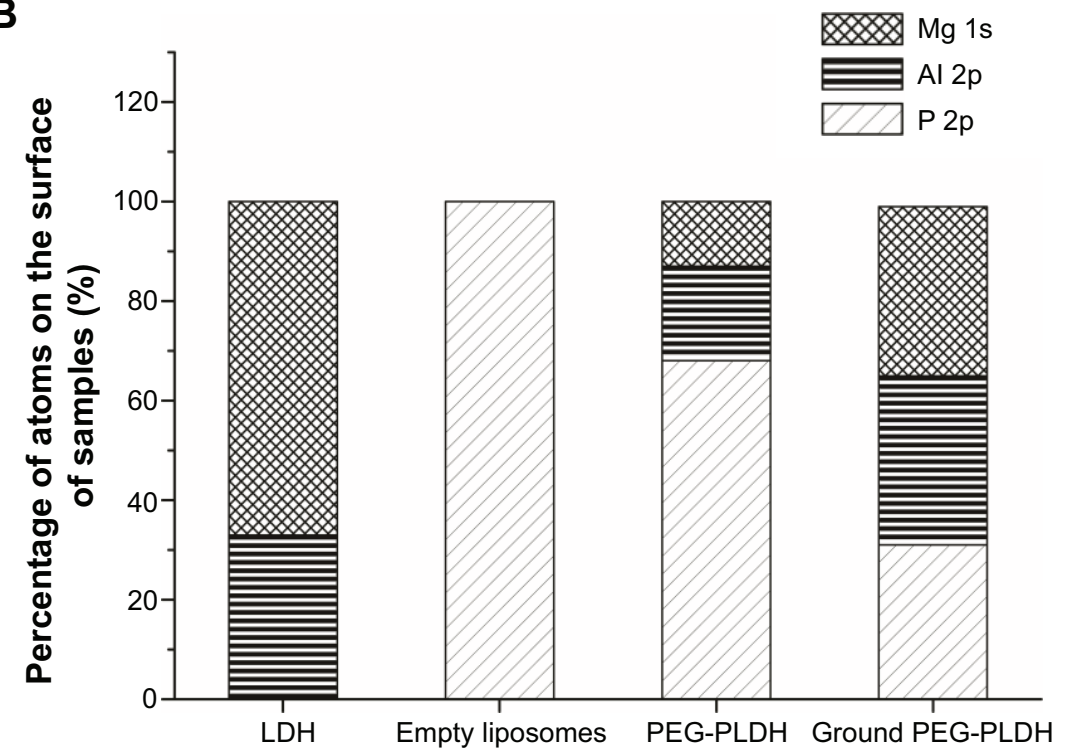

P 2p
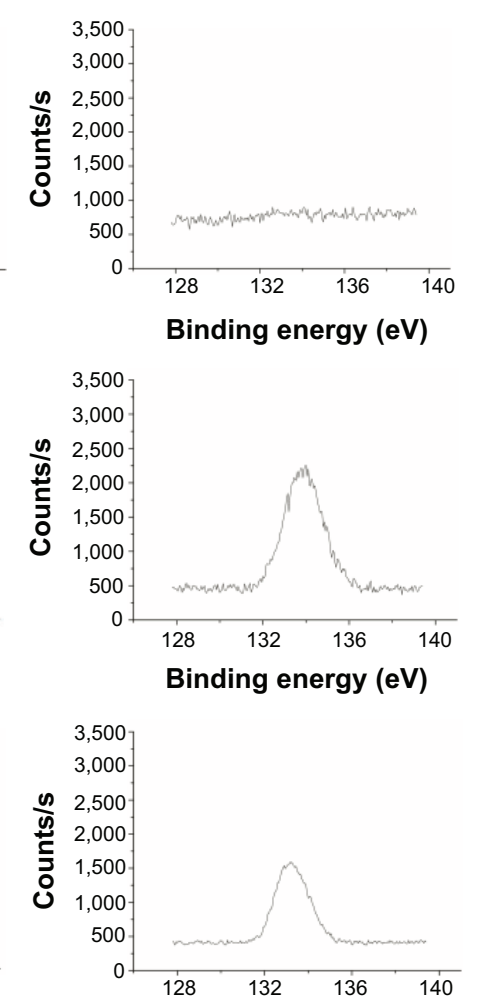

Binding energy (eV)
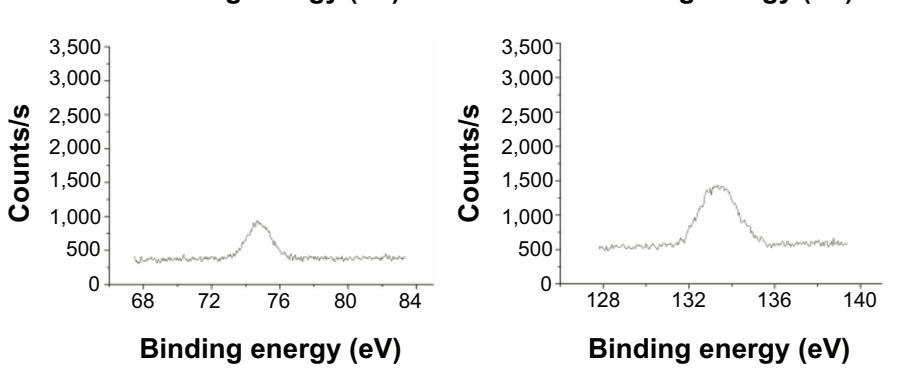

Binding energy (eV)

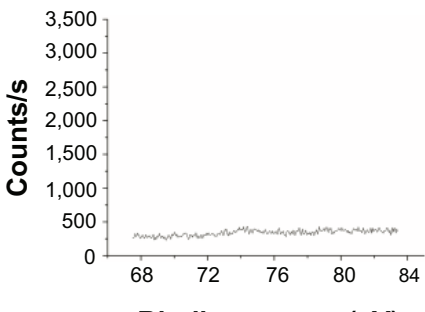

Binding energy (eV)

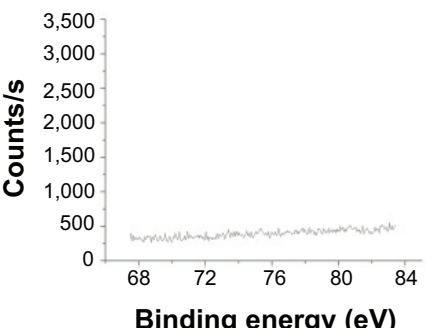

$\mathrm{Mg} 1 \mathrm{~s}$ 


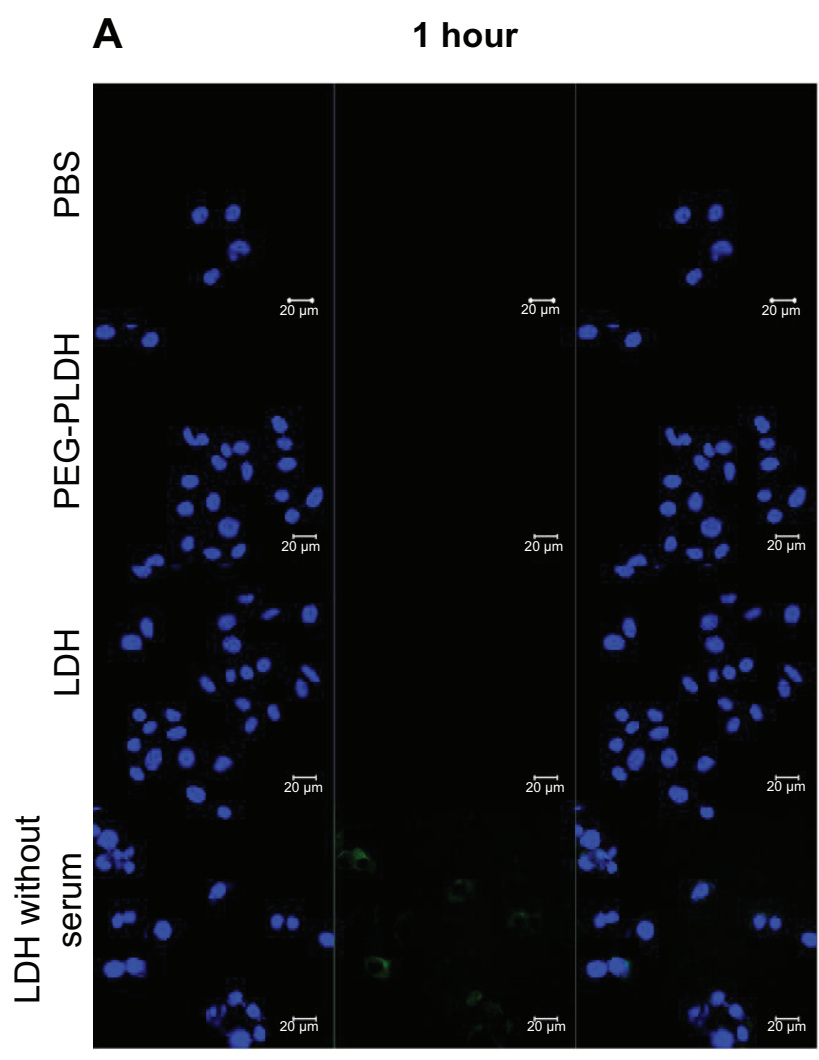

\section{B \\ 4 hours}

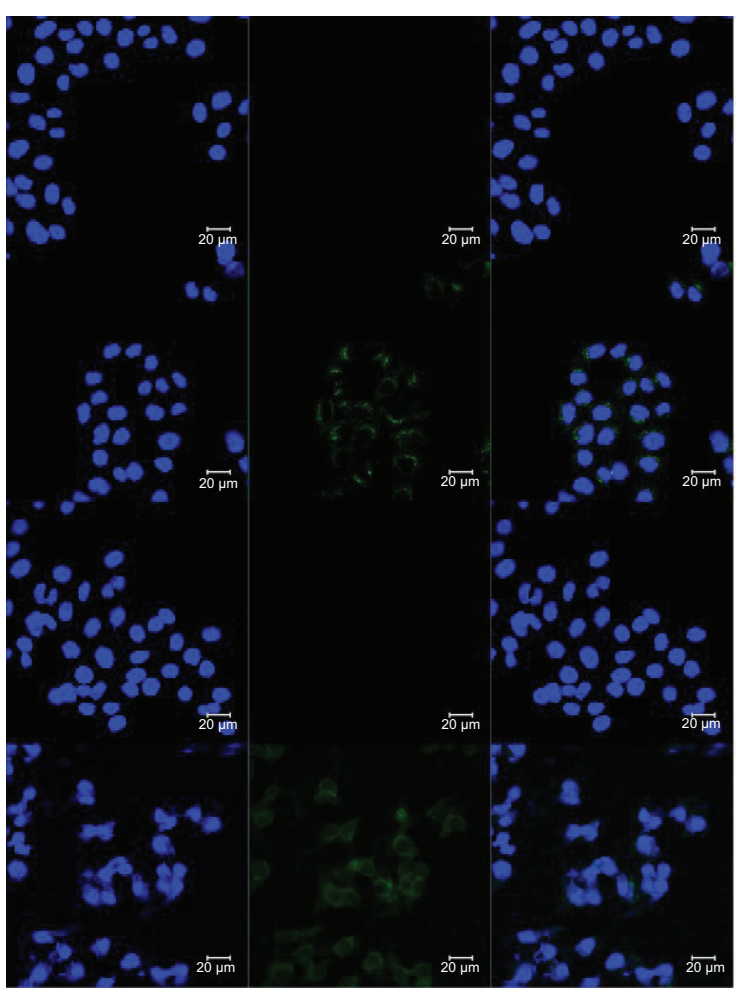

D

48 hours

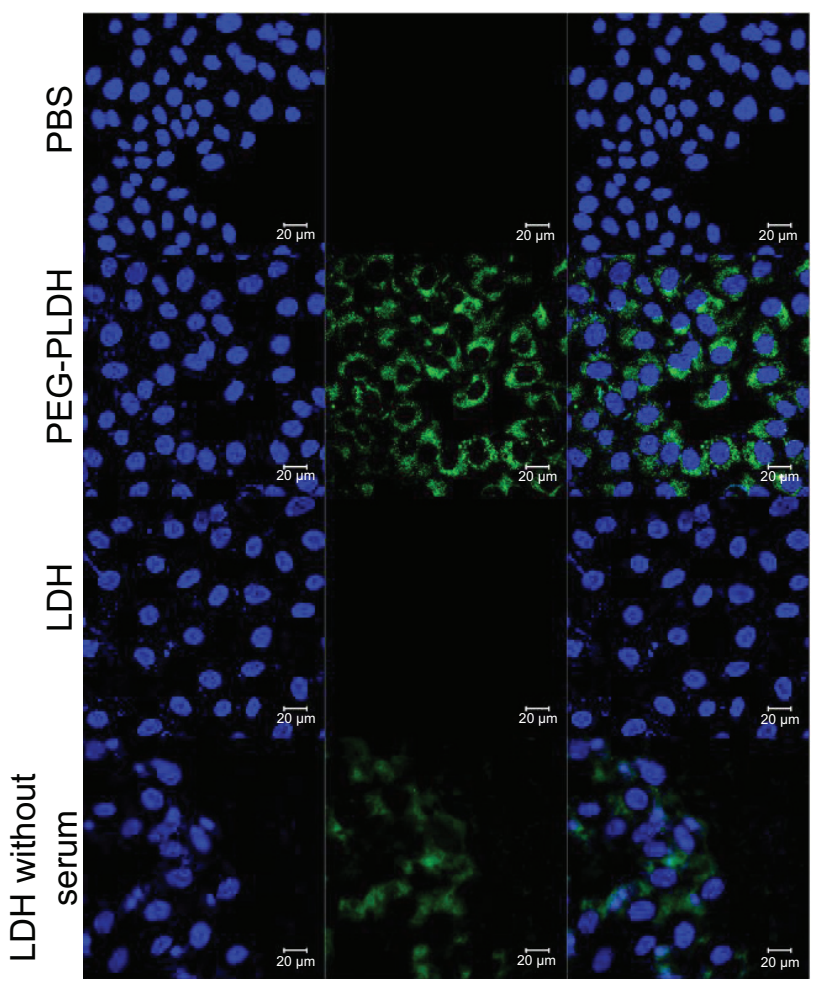

Figure 4 Cell uptake of LDH and PEG-PLDH in the presence of serum, and LDH in the absence of serum, in a HeLa cell line for I hour (A), 4 hours (B), 24 hours (C), and 48 hours (D), imaged by confocal microscopy.

Notes: LDH and PEG-PLDH nanoparticles were loaded with FITC (green). Nuclei (blue) were stained by DAPI. Scale bar, $20 \mu \mathrm{m}$.

Abbreviations: DAPI, 4',6-diamidino-2-phenylindole; FITC, fluorescein isothiocyanate; LDH, layered double hydroxide; PBS, phosphate-buffered saline; PEG, polyethylene glycol; PEG-PLDH, PEGylated phospholipid-coated layered double hydroxide. 

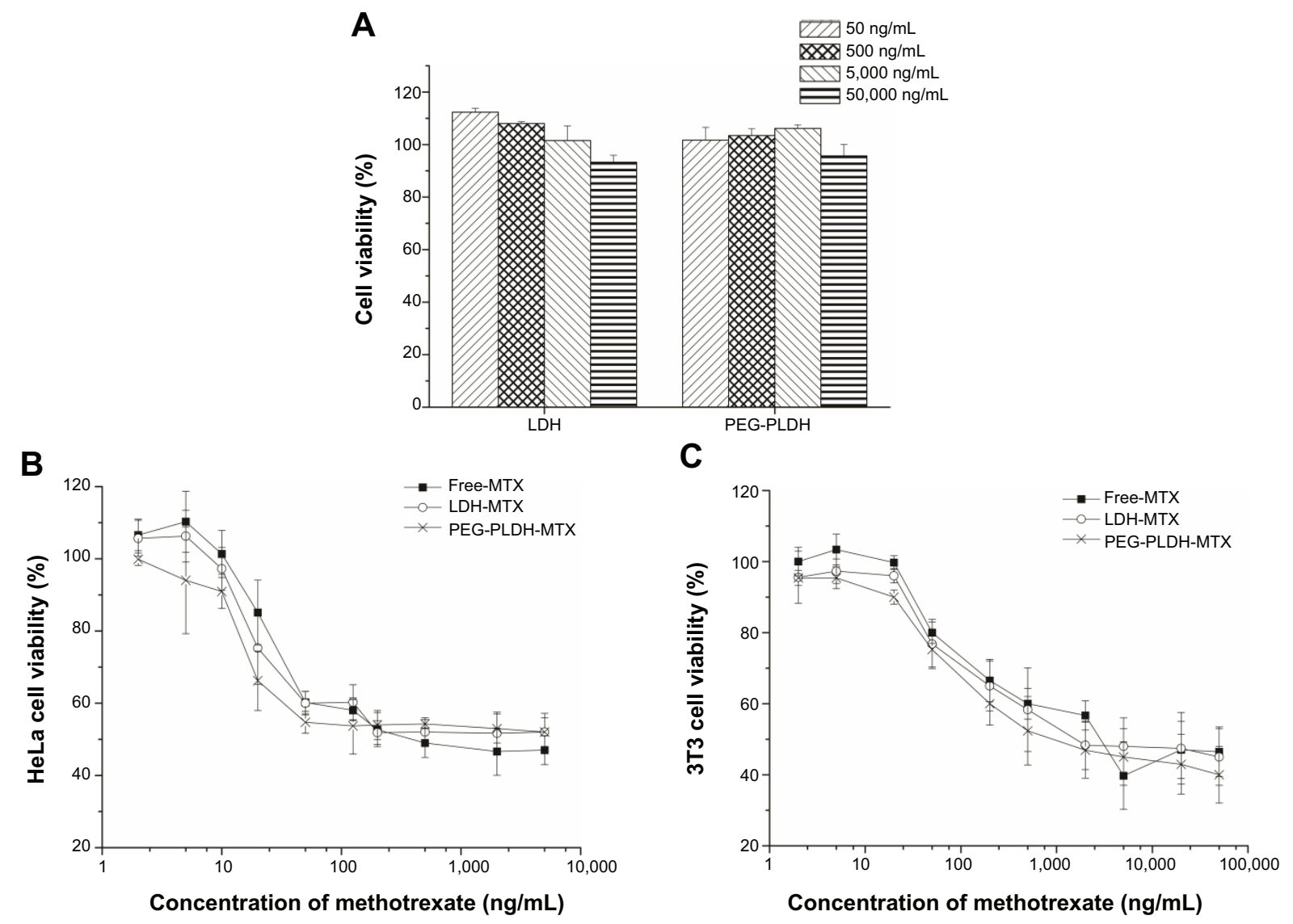

Figure 5 Cell viability.

Notes: Effect of MTX-free nanoparticles on the viability of HeLa cells (A). Effect of MTX formulations on the viability of HeLa (B) and $3 T 3$ (C) cells. The data represent the mean \pm SD of three wells and are representative of three independent experiments.

Abbreviations: LDH, layered double hydroxide; MTX, methotrexate; PEG, polyethylene glycol; PEG-PLDH, PEGylated phospholipid-coated layered double hydroxide; SD, standard deviation.

could be prevented by coating LDH nanoparticles with lipid membrane (Figure 6).

\section{In vivo pharmacokinetic study}

The plasma clearance curves of free-MTX, LDH-MTX, and PEG-PLDH-MTX nanoparticles in Sprague-Dawley rats

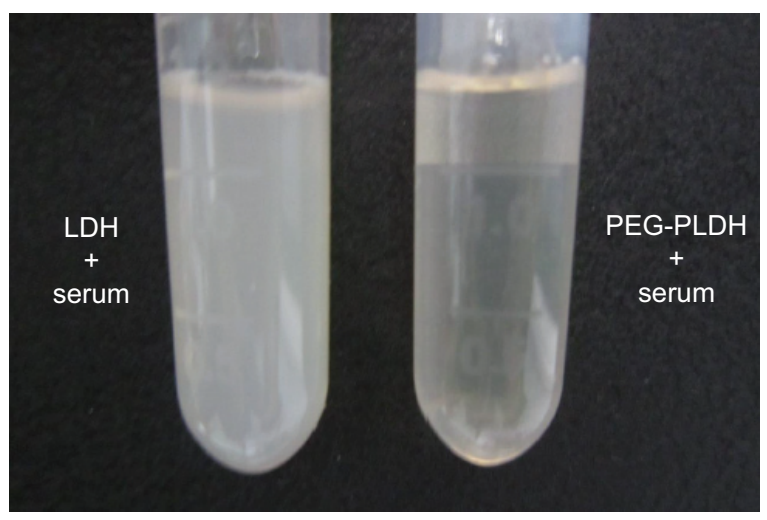

Figure 6 Interaction of nanoparticles with plasma proteins. Notes: Serum was mixed with nanoparticles at ratio of I00:I.

Abbreviations: LDH, layered double hydroxide; PEG, polyethylene glycol; PEGPLDH, PEGylated phospholipid-coated layered double hydroxide. are shown in Figure 7. Data showed that PEG-PLDH-MTX achieved a larger area under the concentration - time curve (AUC) $(P<0.001)$ and had longer half-life $(P<0.001)$, but both free-MTX and LDH-MTX were quickly eliminated from circulation. A very rapid decrease in the MTX concentration was observed in 5 minutes for both free-MTX and LDHMTX. In contrast, the PEG-PLDH delivery system remained in circulation 8 hours after injection, indicating markedly delayed blood clearance.

\section{In vivo therapeutic efficacy}

The antitumor effect of MTX-loaded PEG-PLDH nanoparticles was assessed in vivo using subcutaneous S-180 tumor-bearing mice. The survival rates are represented in a Kaplan-Meier plot in Figure 8A. These results suggest that PEG-PLDH nanoparticles are much safer than positively charged LDH nanoparticles. Mice treated with LDH-MTX nanoparticles died immediately after the third or fourth injection and could not survive more than 9 days. Vaso-occlusion was also found to occur, and precipitation was observed when LDH nanoparticles were mixed with serum (Figure 6). 


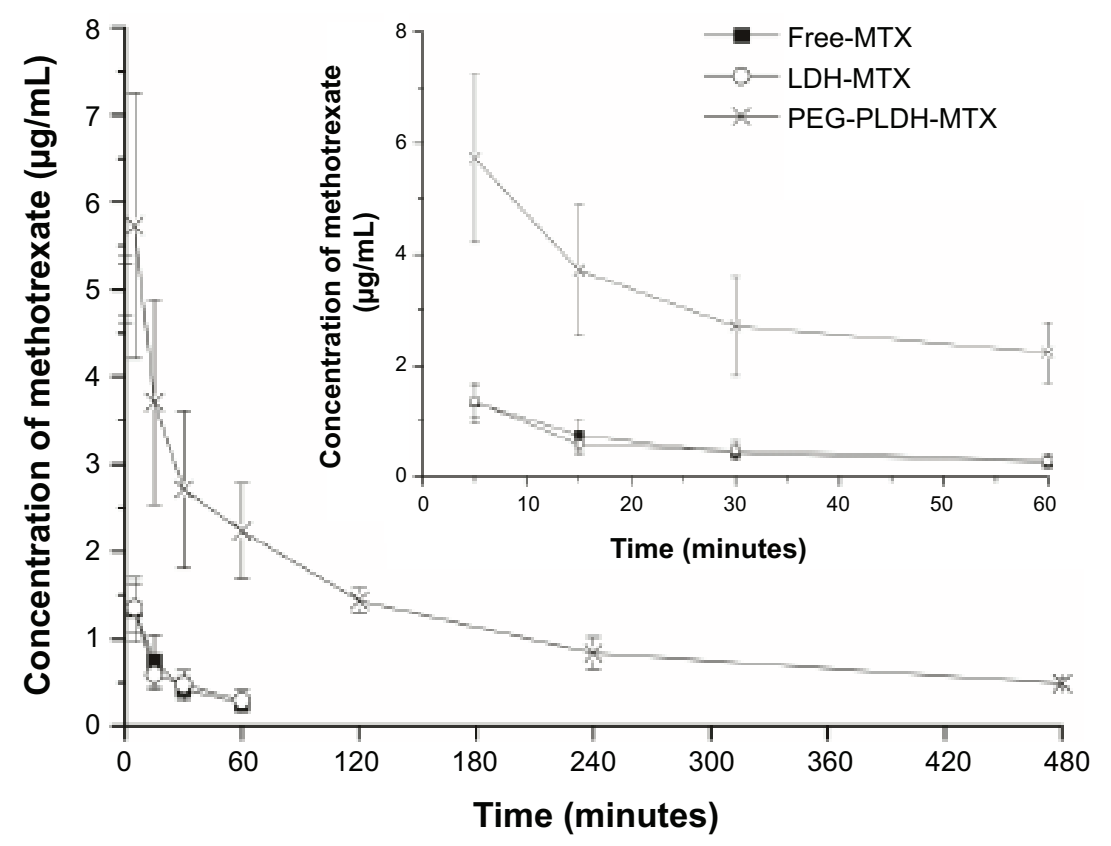

Figure 7 Plasma concentration-time curves after IV administration of MTX, LDH-MTX, and PEG-PLDH-MTX to Sprague-Dawley rats (MTX =2.5 mg/kg) ( $\mathrm{n}=6)$.

Abbreviations: IV, intravenous; LDH, layered double hydroxide; MTX, methotrexate; PEG, polyethylene glycol; PEG-PLDH, PEGylated phospholipid-coated layered double hydroxide.
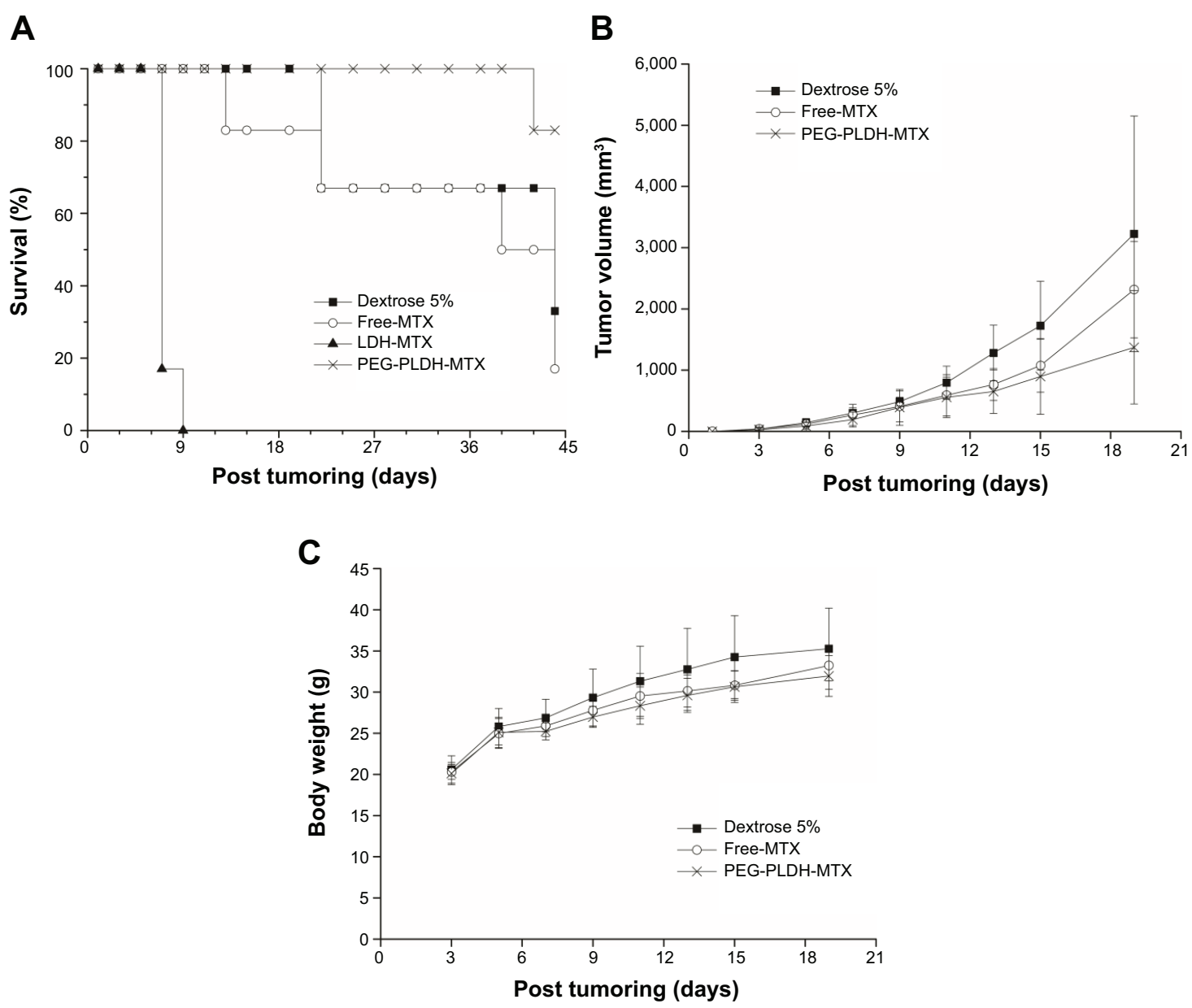

Figure $8 \mathrm{In}$ vivo therapeutic efficacy of various formulations in Kunming mice bearing S-180 subcutaneous tumor after IV administration of a single dose of $2 \mathrm{mg} / \mathrm{kg}$ MTX or dextrose $5 \%$ every other day from day 3 after tumor inoculation. (A) Survival curve, (B) tumor growth rate, and (C) change in animal body weight.

Note: Data represented as mean $\pm S D(n=6)$.

Abbreviations: IV, intravenous; MTX, methotrexate; SD, standard deviation; LDH, layered double hydroxide; PEG, polyethylene glycol; PEG-PLDH, PEGylated phospholipidcoated layered double hydroxide. 
Tumor volumes demonstrated that the PEG-PLDH-MTX treatment suppressed tumor growth significantly compared with $5 \%$ dextrose $(P<0.05)$, while the free-MTX treatment had no obvious antitumor effect compared with $5 \%$ dextrose $(P>0.05)$ (Figure $8 \mathrm{~B})$. Body weight was uniform throughout the study, indicating no apparent general toxicity (Figure 8C).

\section{Conclusion}

Positive charges were found to drastically hamper both the cancer cell uptake and therapeutic outcome of LDH nanoparticles carrying a cytotoxic drug. Based on these observations, it is here proposed that a coating of lipid membrane could be a simple and versatile approach to preventing unwanted interactions between positively charged LDH nanoparticles and negatively charged proteins in the blood, particularly reticuloendothelial system. It may be possible to prolong circulation time and so enhance tumor inhibition. Though the lipid membrane may reduce the rate of nanoparticle-cell interactions, naked LDH nanoparticles can only enter cells in the absence of negatively charged proteins.

In summary, the current study revealed that coating LDH nanoparticles with lipids results in slower blood clearance and more effective cancer drug delivery. Herein, a PEG-PLDH delivery system was introduced, and it showed promises as a tool for cancer therapy.

\section{Acknowledgments}

We are grateful for financial support from the National Natural Science Foundation of China (grant numbers 81302715/ H3008 and 81173003/H3008). We thank LetPub (www.letpub.

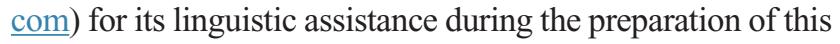
manuscript.

\section{Disclosure}

The authors report no conflicts of interest in this work.

\section{References}

1. Liu X, Fan B, Gao S, Li R. Transesterification of tributyrin with methanol over $\mathrm{MgAl}$ mixed oxides derived from $\mathrm{MgAl}$ hydrotalcites synthesized in the presence of glucose. Fuel Processing Technology. 2013; 106:761-768.

2. Sels B, De Vos D, Buntinx M, PierardF, Kirsch-De Mesmaeker A, Jacobs P. Layered double hydroxides exchanged with tungstate as biomimetic catalysts for mild oxidative bromination. Nature. 1999;400:855-857.

3. Drenkova-Tuhtan A, Mandel K, Paulus A, et al. Phosphate recovery from wastewater using engineered superparamagnetic particles modified with layered double hydroxide ion exchangers. Water Res. 2013;47(15): 5670-5677.

4. Shin HS, Kim MJ, Nam SY, Moon HC. Phosphorus removal by hydrotalcite-like compounds (HTLcs). Water Sci Technol. 1996;34(1-2): 161-168.
5. Jia C, Qian Y, Chen X, Liu Y. Flame retardant ethylene-vinyl acetate composites based on layered double hydroxides with zinc hydroxystannate. Polymer Engineering and Science. Epub 2014, Jan 22.

6. Zammarano M, Franceschi M, Bellayer S, Gilman JW, Meriani S. Preparation and flame resistance properties of revolutionary self-extinguishing epoxy nanocomposites based on layered double hydroxides. Polymer. 2005;46(22):9314-9328.

7. Ladewig K, Xu ZP, Lu GQ. Layered double hydroxide nanoparticles in gene and drug delivery. Expert Opin Drug Deliv. 2009;6(9): 907-922.

8. Rives V, Del Arco M, Martín C. Layered double hydroxides as drug carriers and for controlled release of non-steroidal antiinflammatory drugs (NSAIDs): a review. J Control Release. 2013;169(1-2):28-39.

9. Seftel EM, Popovici E, Mertens M, et al. Zn-Al layered double hydroxides: synthesis, characterization and photocatalytic application. Microporous Mesoporous Mater. 2008;113(1-3):296-304.

10. Auerbach MS, Carrado KA, Dutta PK, editors. Handbook of Layered Materials. Boca Raton, FL: CRC Press; 2004.

11. Cavani F, Trifirò F, Vaccari A. Hydrotalcite-type anionic clays: preparation, properties and applications. Catal Today. 1991;11(2):173-301.

12. Xu ZP, Stevenson G, Lu CQ, Lu GQ. Dispersion and size control of layered double hydroxide nanoparticles in aqueous solutions. $J$ Phys Chem B. 2006;110(34):16923-16929.

13. Choi SJ, Oh JM, Choy JH. Biocompatible nanoparticles intercalated with anticancer drug for target delivery: pharmacokinetic and biodistribution study. J Nanosci Nanotechnol. 2010;10(4):2913-2916.

14. Oh JM, Choi SJ, Kim ST, Choy JH. Cellular uptake mechanism of an inorganic nanovehicle and its drug conjugates: enhanced efficacy due to clathrin-mediated endocytosis. Bioconjug Chem. 2006;17(6): 1411-1417.

15. Qin L, Xue M, Wang W, et al. The in vitro and in vivo anti-tumor effect of layered double hydroxides nanoparticles as delivery for podophyllotoxin. Int J Pharm. 2010;388(1-2):223-230.

16. Xue YH, Zhang R, Sun XY, Wang SL. The construction and characterization of layered double hydroxides as delivery vehicles for podophyllotoxins. J Mater Sci Mater Med. 2008;19(3): 1197-1202.

17. Ladewig K, Niebert M, Xu ZP, Gray PP, Lu GQ. Efficient siRNA delivery to mammalian cells using layered double hydroxide nanoparticles. Biomaterials. 2010;31(7):1821-1829.

18. Ladewig K, Niebert M, Xu ZP, Gray PP, Lu GQ. Controlled preparation of layered double hydroxide nanoparticles and their application as gene delivery vehicles. Appl Clay Sci. 2010;48(1-2):280-289.

19. Li B, Wu P, Ruan B, Liu P, Zhu N. Study on the adsorption of DNA on the layered double hydroxides (LDHs). Spectrochim Acta A Mol Biomol Spectrosc. 2014;121:387-393.

20. Wong Y, Markham K, Xu ZP, et al. Efficient delivery of siRNA to cortical neurons using layered double hydroxide nanoparticles. Biomaterials. 2010;31(33):8770-8779.

21. Oh JM, Choi SJ, Lee GE, Kim JE, Choy JH. Inorganic metal hydroxide nanoparticles for targeted cellular uptake through clathrin-mediated endocytosis. Chem Asian J. 2009;4(1):67-73.

22. Xu ZP, Niebert M, Porazik K, et al. Subcellular compartment targeting of layered double hydroxide nanoparticles. J Control Release. 2008; 130(1):86-94.

23. Chung HE, Park DH, Choy JH, Choi SJ. Intracellular trafficking pathway of layered double hydroxide nanoparticles in human cells: size-dependent cellular delivery. Appl Clay Sci. 2012;65-66:24-30.

24. Taratula O, Garbuzenko OB, Kirkpatrick P, et al. Surface-engineered targeted PPI dendrimer for efficient intracellular and intratumoral siRNA delivery. J Control Release. 2009;140(3):284-293.

25. Alexis F, Pridgen E, Molnar LK, Farokhzad OC. Factors affecting the clearance and biodistribution of polymeric nanoparticles. Mol Pharm. 2008;5(4):505-515.

26. Kakizawa Y, Furukawa S, Ishii A, Kataoka K. Organic-inorganic hybridnanocarrier of siRNA constructing through the self-assembly of calcium phosphate and PEG-based block aniomer. J Control Release. 2006; 111(3):368-370. 
27. Schmidt HT, Gray BL, Wingert PA, Ostafin AE. Assembly of aqueouscored calcium phosphate nanoparticles for drug delivery. Chem Mater. 2004;16(24):4942-4947.

28. Hadinoto K, Sundaresan A, Cheow WS. Lipid-polymer hybrid nanoparticles as a new generation therapeutic delivery platform: a review. Eur J Pharm Biopharm. 2013;85(3 Pt A):427-443.

29. Xu ZP, Jin Y, Liu S, Hao ZP, Lu GQ. Surface charging of layered double hydroxides during dynamic interactions of anions at the interfaces. J Colloid Interface Sci. 2008;326(2):522-529.

30. Hunter RH. Zeta potential in colloid science. New York: Academic Press, 1981.

31. Guo H, Zhang D, Li C, et al. Self-assembled nanoparticles based on galactosylated O-carboxymethyl chitosan-graft-stearic acid conjugates for delivery of doxorubicin. Int J Pharm. 2013;458(1): 31-38.

32. Zhang J, Dong G, Thurber A, et al. Tuning the properties of $\mathrm{ZnO}$, hematite, and Ag nanoparticles by adjusting the surface charge. $A d v$ Mater. 2012;24(9):1232-1237.

33. Layre A, Couvreur P, Chacun H, et al. Novel composite core-shell nanoparticles as busulfan carriers. J Control Release. 2006;111(3): 271-280.
34. Bowey K, Tanguay JF, Tabrizian M. 2-Dioleoyl-sn-glycero-3phosphocholine-based nanoliposomes as an effective delivery platform for 17ß-estradiol. Eur J Pharm Biopharm. 2014;86(3):369-375.

35. Yu Z, Schmaltz RM, Bozeman TC, et al. Selective tumor cell targeting by the disaccharide moiety of bleomycin. JAm Chem Soc. 2013;135(8): 2883-2886.

36. Naguib YW, Cui Z. Nanomedicine: The promise and challenges in cancer chemotherapy. In: Capco DG, Chen Y, editors. Nanomaterial: Impacts on Cell Biology and Medicine. Dordrecht: Springer Netherlands; 2014:207-233.

37. Sabharanjak S, Mayor S. Folate receptor endocytosis and trafficking. Adv Drug Deliv Rev. 2004;56(8):1099-1109.

38. Zhao R, Gao F, Hanscom M, Goldman ID. A prominent low-pH methotrexate transport activity in human solid tumors: contribution to the preservation of methotrexate pharmacologic activity in $\mathrm{HeLa}$ cells lacking the reduced folate carrier. Clin Cancer Res. 2004;10(2): 718-727.

39. Taratula O, Dani RK, Schumann C, et al. Multifunctional nanomedicine platform for concurrent delivery of chemotherapeutic drugs and mild hyperthermia to ovarian cancer cells. Int J Pharm. 2013; 458(1):169-180. 


\section{Supplementary material}

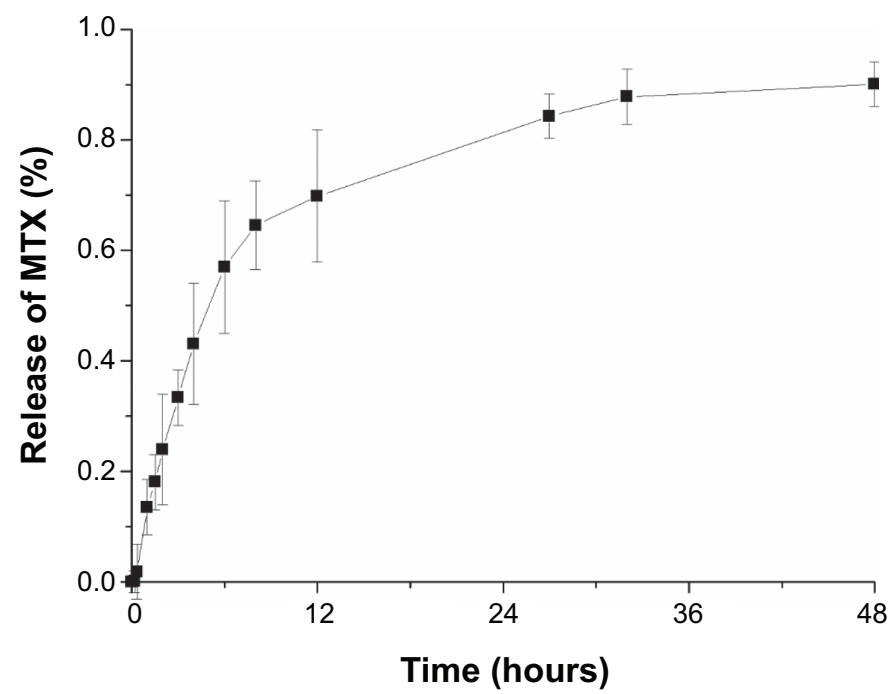

Figure $\mathbf{S I}$ In vitro release kinetics of drug from LDH-MTX nanoparticles in phosphate buffer solutions $(\mathrm{pH} 7.4)$ at $37^{\circ} \mathrm{C}$.

Abbreviations: LDH, layered double hydroxide; MTX, methotrexate.

\section{Publish your work in this journal}

The International Journal of Nanomedicine is an international, peerreviewed journal focusing on the application of nanotechnology in diagnostics, therapeutics, and drug delivery systems throughout the biomedical field. This journal is indexed on PubMed Central, MedLine, CAS, SciSearch $®$, Current Contents ${ }^{\circledR} /$ Clinical Medicine,
Journal Citation Reports/Science Edition, EMBase, Scopus and the Elsevier Bibliographic databases. The manuscript management system is completely online and includes a very quick and fair peer-review system, which is all easy to use. Visit http://www.dovepress.com/ testimonials.php to read real quotes from published authors. 